\title{
Conservation implications for the Himalayan wolf Canis (lupus) himalayensis based on observations of packs and home sites in Nepal
}

\author{
Geraldine Werhahn, Naresh Kusi \\ Claudio Sillero-Zubiri and David W. Macdonald
}

\begin{abstract}
We provide insights into pack composition and den site parameters of the Himalayan wolf Canis (lupus) himalayensis based on observations of free-ranging wolves in three study areas in Nepal. We combine this with a social survey of the local Buddhist communities regarding human-carnivore conflict, to draw inferences for conservation practice in the Nepalese Himalayas. We recorded eight wolf packs (with an average composition of two adults and three pups), and found five home sites in high-altitude shrubland patches within alpine grasslands at 4,270-4,940 m altitude. There was a spatial-temporal overlap of wolf home sites and livestock herding during spring and summer, which facilitated human-wolf conflict. The litters of three out of five wolf packs found in Dolpa during 2016 were killed by local people in the same year. In Nepal compensation is offered for depredation by snow leopards Panthera uncia, with associated lowering of negative attitudes, but not for depredation by wolves. We recommend the implementation of financial and educational conservation schemes for all conflict-causing carnivores across the Himalayan regions of Nepal.
\end{abstract}

Keywords Canis (lupus) himalayensis, conflict, conservation, denning, Himalayan wolf, Nepal, social survey, wolf pack

\section{Introduction}

7 he Himalayan wolf is a distinct lineage occurring in the 1 Himalayas and on the Tibetan Plateau. Genetic evidence supporting its classification as a separate taxon, Canis (lupus) himalayensis, is accumulating (Sharma et al., 2004; Aggarwal et al., 2007; Werhahn et al., 2017). The distribution range, population status and ecology of this wolf remain poorly known (Fox \& Chundawat, 1995; Jnawali

Geraldine Werhahn (Corresponding author), Claudio Sillero-Zubiri* and David W. Macdonald Wildlife Conservation Research Unit, Department of Zoology, University of Oxford, The Recanati-Kaplan Centre, Tubney House, Tubney OX13 5QL, UK. E-mail geraldine.werhahn@zoo.ox.ac.uk

NARESH Kusi Resources Himalaya Foundation, Sanepa, Lalitpur, Nepal

*Also at: IUCN SSC Canid Specialist Group, Oxford, UK

Received 4 April 2017. Revision requested 19 May 2017.

Accepted 22 June 2017. First published online 20 September 2017. et al., 2011). Potential wolf habitat exists across large parts of the Nepalese Himalayas $(>70 \%)$ but the size of the wolf population in the country remains unknown; there are genetically verified records from Mustang, Dolpa and Humla (Subba, 2012; Chetri et al., 2016; Subba et al., 2017; Werhahn et al., 2017), and sign surveys have indicated wolf presence in Manaslu, Api Nampa and Kanchenjunga Conservation Areas (Subba et al., 2017; GW \& NK, pers. obs., 2016).

The wolf is protected as a priority species in Nepal under the National Parks and Wildlife Conservation Act 2029 (1973) and is categorized nationally as Critically Endangered (GoN, 1973; Jnawali et al., 2011). Nepal's wildlife damage relief guidelines include the wolf in the national compensation scheme in its first amendment (GoN, 2015), but this legal basis awaits implementation.

Little is known about the denning ecology of the Himalayan wolf in the remote and rugged high-altitude landscapes of the Himalayas and the Tibetan Plateau (Werhahn et al., 2017) but similarities to the Holarctic grey wolf Canis lupus spp. are expected (Mech \& Boitani, 2003).

\section{Methods}

This study was conducted in Humla and Dolpa districts in north-western Nepal, and Kanchenjunga Conservation Area in north-eastern Nepal, during the spring and summer seasons of 2014-2016 (Fig. 1). The Humla site lies outside the protected area system, whereas large parts of the Dolpa site are situated within Shey Phoksundo National Park, and Kanchenjunga Conservation Area is a community-managed conservation area. All three study areas are used seasonally by herders in the late spring and summer to graze yak Bos grunniens, cattle Bos taurus and goats Capra aegagrus hircus (Bauer, 2004). The vegetation in these areas is dominated by alpine grasslands and steppes interspersed with patches of shrubland (Miehe et al., 2016), at 3,600-5,600 m altitude. In Humla we searched $384 \mathrm{~km}^{2}$ for wolves (walking $420 \mathrm{~km}$ in 2014 and $605 \mathrm{~km}$ in 2015), in Dolpa 1,088 km² (walking $262 \mathrm{~km}$ in 2015 and $810 \mathrm{~km}$ in 2016), and in Kanchenjunga Conservation Area $368 \mathrm{~km}^{2}$ (walking $355 \mathrm{~km}$ in 2016).

We collected data on wolf packs through direct observations, examination of home sites, and reports of sightings by local people, which were later verified by examining distances between recorded home sites. Home sites, 


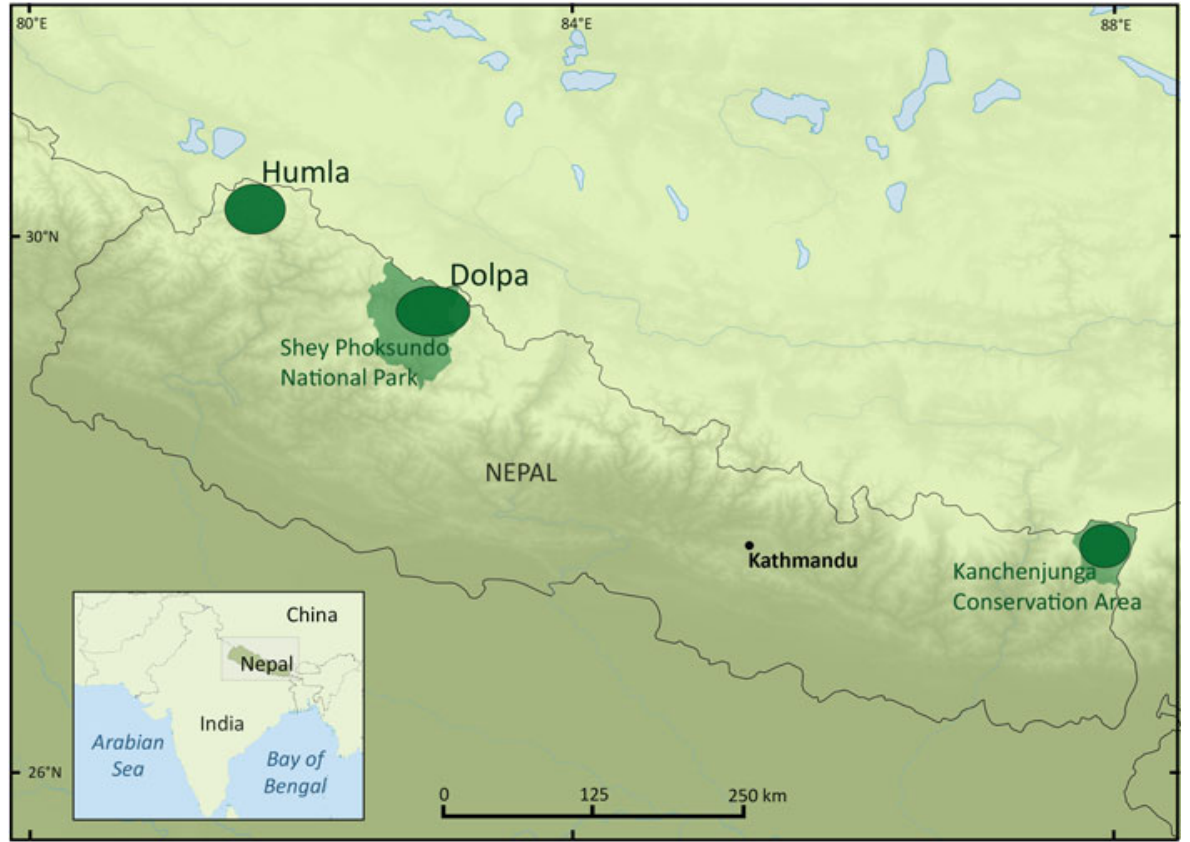

FIG. 1 Locations of the three study sites in the Himalayas in Nepal: Humla (outside the protected area network), Dolpa (partly within Shey Phoksundo National Park), and the community-managed Kanchenjunga Conservation Area. comprising den and rendezvous sites, were characterized by abundant recent scats of pups and adults, along with bones and other food remains. Den sites additionally comprised a den cave (Mech \& Boitani, 2003).

To investigate human-carnivore conflict we conducted semi-structured social surveys during the field work expeditions of 2014-2016, with 72 respondents from the local Buddhist communities (32 (44\%) in Humla, 27 (38\%) in Dolpa, and 13 (18\%) in Kanchenjunga Conservation Area). Respondents comprised herders (67\%), monks/lamas (10\%), teachers $(4 \%)$, business people $(11 \%)$, construction workers (5\%) and hoteliers (3\%). Respondents were $20-78$ years of age and comprised $25 \%$ females and $75 \%$ males. Survey questions explored perceptions of trends in the wolf population and depredation incidents, and spatial and temporal depredation hotspots, and respondents were asked to rank predators based on the magnitude of depredation problems they cause.

\section{Results}

The eight packs encountered in Nepal consisted, on average, of five individuals: an adult pair accompanied by a mean of 2.9 \pm SD 0.6 pups of the current year (Table 1, Plate 1). According to our observations, Himalayan wolves in Nepal give birth between mid April and mid May $(n=4)$. The mean distance between the home sites of four adjacent wolf packs in Dolpa was $19.6 \pm$ SD $5.5 \mathrm{~km}(\mathrm{n}=4)$. All home sites were situated in patches of rolling alpine shrubland dominated by Caragana, Lonicera, Astragalus, Salix and Juniperus spp. within alpine grasslands and in proximity to water (Table 2).
In Dolpa and Kanchenjunga Conservation Area a perceived increase in the wolf population was reflected in a perceived increase in depredation by wolves. In Humla, however, a perceived decrease in the wolf population correlated with a perceived decrease in depredation (Figs 2 \& 3); local people attributed this decrease in depredation largely to the lower numbers of livestock kept now compared to the past. In Humla and Dolpa snow leopards were ranked as the most problematic carnivore, followed by wolves, and vice versa in Kanchenjunga Conservation Area. In Humla, depredation by wolves was reported to be at its highest during the summer. Respondents in Kanchenjunga Conservation Area reported the highest depredation rates in winter, followed by spring/summer, whereas no seasonal pattern emerged in Dolpa (Fig. 3).

\section{Discussion}

The social life of Himalayan wolves is characterized by small packs (i.e. family groups; Plate 1), similar to packs of Holarctic grey wolves, golden jackals Canis aureus and coyotes Canis latrans (Sillero-Zubiri et al., 2004). The Himalayan wolf packs observed were comparatively smaller than Holarctic grey wolf packs, which commonly comprise 6-12 individuals (Sillero-Zubiri et al., 2004). Factors potentially influencing pack size may include prey abundance and size, wolf mortality, and prompt dispersal of yearlings (Fuller, 1989; Jędrzejewski et al., 2002).

The home sites used by these Himalayan wolf packs were probably chosen for their quality in respect to hiding cover, structural diversity and water accessibility, similar to recorded characteristics of grey wolf den sites (Trapp et al., 2008). 
TABLE 1 Pack composition of eight Himalayan wolf Canis (lupus) himalayensis packs in three areas in Nepal: Dolpa (within and outside Shey Phoksundo National Park), Humla and Kanchenjunga Conservation Area (Fig. 1), with type of evidence, and year recorded.

\begin{tabular}{|c|c|c|c|}
\hline Location & Pack composition & Type of evidence & Year \\
\hline \multicolumn{4}{|l|}{ Dolpa district } \\
\hline \multicolumn{4}{|l|}{ Shey Phoksundo National Park } \\
\hline Komas & 2 adults, 3 pups* & Reported by local people \& personal observation & 2016 \\
\hline Bhijer & 2 adults, 3 pups & Personal observation & 2016 \\
\hline Nisalgaon & 2 adults, 2 pups ${ }^{*}$ & Reported by local people \& personal observation & 2016 \\
\hline Polte & 2 adults, 3 pups & Personal observation & 2016 \\
\hline Charka Tulsi & Unknown no. of adults, 3 pups ${ }^{*}$ & Reported by local people & 2016 \\
\hline \multicolumn{4}{|l|}{ Humla district } \\
\hline Gyau & Unknown no. of adults, 3 pups & Personal observation & 2015 \\
\hline Ngin & 2 adults, 4 pups & Personal observation & 2014 \\
\hline \multicolumn{4}{|l|}{ Taplejung district } \\
\hline Lhonak (Kanchenjunga Conservation Area) & 2 adults, 3 pups & Reported by local people & 2016 \\
\hline
\end{tabular}

${ }^{*}$ Pups of the year killed through smoking the den

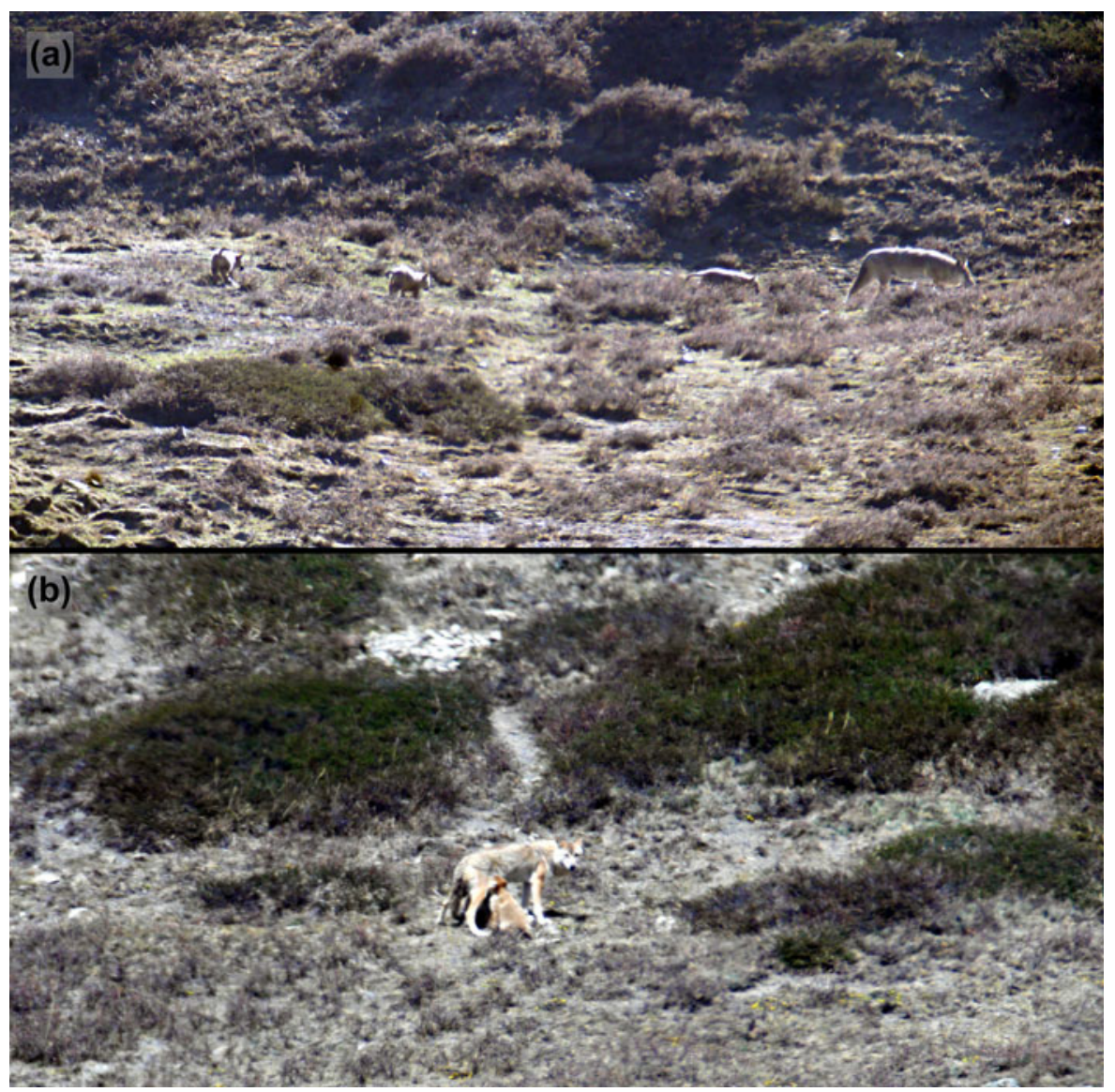

Plate 1 A Himalayan wolf Canis (lupus) himalayensis pack photographed near Bhijer village in Dolpa district of Nepal (Fig. 1) in 2016. (a) A female and her three pups in the morning, and (b) the female suckling her pups. (Photograph by Geraldine Werhahn)
The high-altitude shrublands used by the packs for denning are also used by local people to graze livestock in late spring and summer, a time when the pups are a few weeks old and are restricted to home sites. Pupping packs are less mobile and need ample food. This spatial-temporal overlap of wolf denning with herding, which often involves large numbers of livestock being brought in seasonally, gives rise to human-wolf conflict (Mishra, 1997; GW \& NK, pers. obs., 2014-2016). Livestock competes with, and may displace, wild prey species such as blue sheep Pseudois nayaur, kiang Equus kiang and argali Ovis ammon. Consequently human-wolf conflict is intensified during late spring and summer in the pasturelands.

The social surveys indicated that no compensation for wolf depredation was provided in any of the three study sites, whereas compensation for snow leopard depredation 
TABLE 2 Characteristics of four den sites and one rendezvous site of Himalayan wolves in Dolpa and Humla districts, Nepal (Fig. 1), with type of vegetation, dominant topography, distance to water, elevation, aspect, year of recording, and district.

\begin{tabular}{|c|c|c|c|c|c|c|c|}
\hline Location & Home site type & Vegetation & Dominant topography & Distance to water (m) & Altitude (m) & Aspect & Year \\
\hline \multicolumn{8}{|l|}{ Dolpa } \\
\hline Komas & Den & Shrubland & Hillslope & 1,250 & 4,270 & North & 2016 \\
\hline Bhijer & Den & Shrubland & Hillslope & 50 & 4,790 & South & 2016 \\
\hline Nisalgaon & Den & Shrubland & Hillslope & 40 & 4,650 & South-west & 2016 \\
\hline Polte & Rendezvous & $\begin{array}{l}\text { Shrubland/ } \\
\text { grassland }\end{array}$ & Valley floor & 20 & 4,915 & Flat & 2016 \\
\hline \multicolumn{8}{|l|}{ Humla } \\
\hline Gyau & Den & Shrubland & Hillslope & 280 & 4,940 & South & 2015 \\
\hline
\end{tabular}

(a) Dolpa: wolf population trend

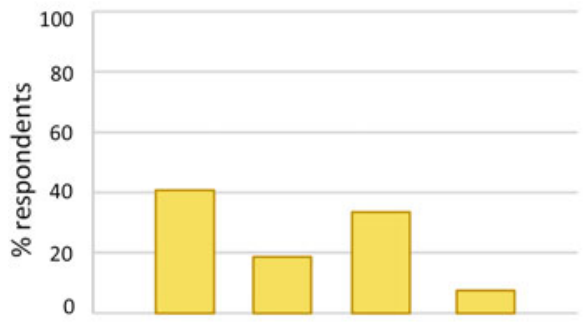

(c) Humla: wolf population trend

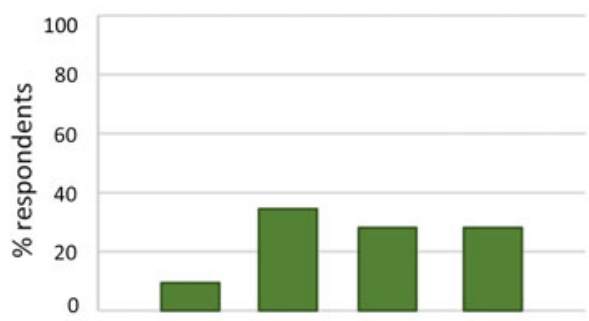

(e) KCA: wolf population trend

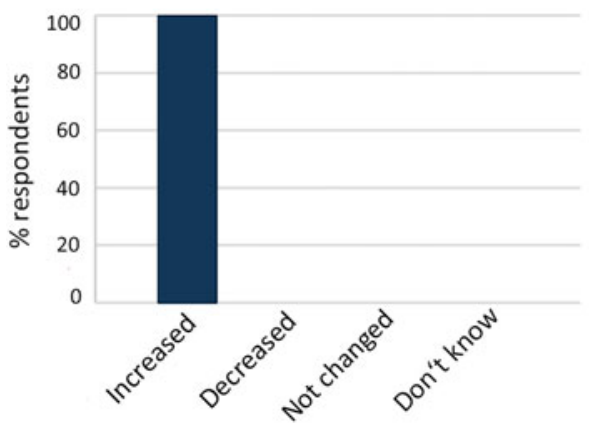

(b) Dolpa: wolf depredation incidents

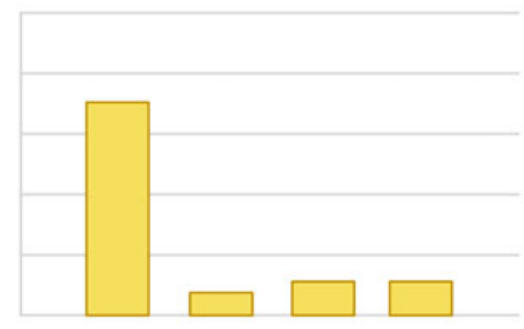

(d) Humla: wolf depredation incidents

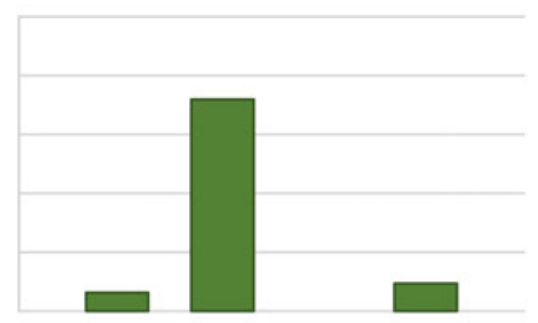

(f) KCA: wolf depredation incidents

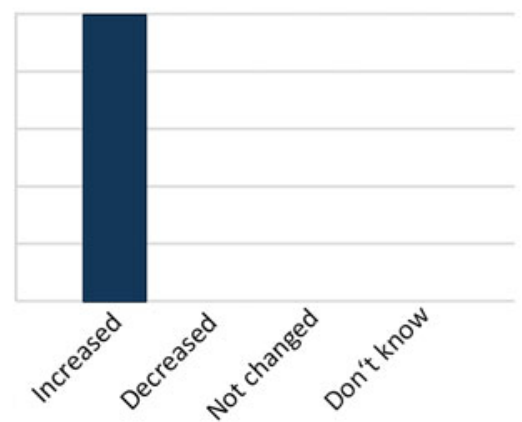

FIG. 2 Wolf Canis (lupus) himalayensis population and depredation trends as reported by local respondents during structured social surveys in Dolpa $(\mathrm{n}=27)$, Humla $(\mathrm{n}=32)$, and Kanchenjunga Conservation Area (KCA; $\mathrm{n}=13$ ). is provided in parts of Shey Phoksundo National Park and in Kanchenjunga Conservation Area (Subba et al., 2017). Killing wolves is often considered to be an act of service towards the entire community, as it is assumed to prevent future livestock depredation.

The entire litters of three out of five wolf packs found in Dolpa in 2016 were killed that same year by local people. The pups were smoked to death by lighting a fire inside the den and blocking the entrance with stones (GW \& NK, pers. obs.; local people, pers. comm., 2016). Schaller (1982) similarly reported persecution of wolves in Dolpa, with local people gathering each spring to look for wolf dens and kill the pups. However, killing wolves is often not an effective means of decreasing livestock depredation and can be counter-productive, because of a perturbation effect (Tuyttens \& Macdonald, 2000) arising from the disrupted pack structure and territorial 
(a) Dolpa: top predator

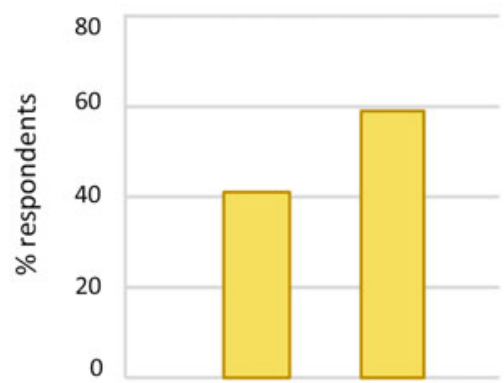

(c) Humla: top predator

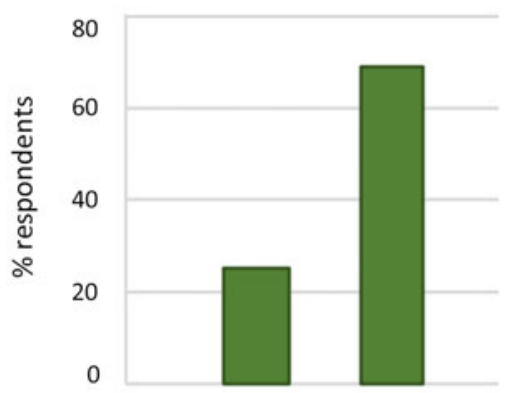

(e) KCA: top predator

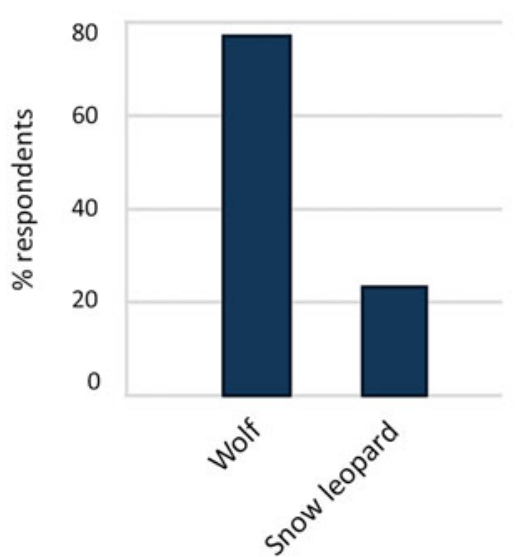

(b) Dolpa: peak season for wolf depredation

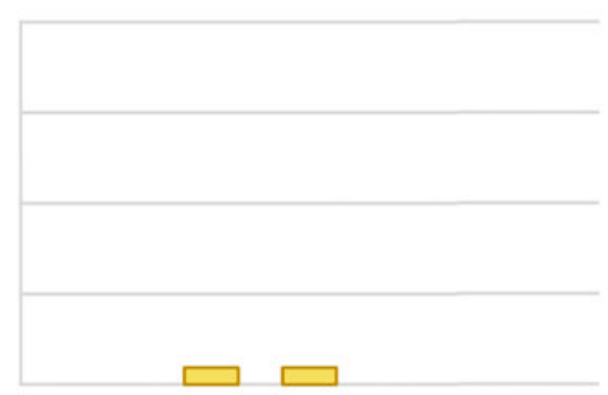

(d) Humla: peak season for wolf depredation

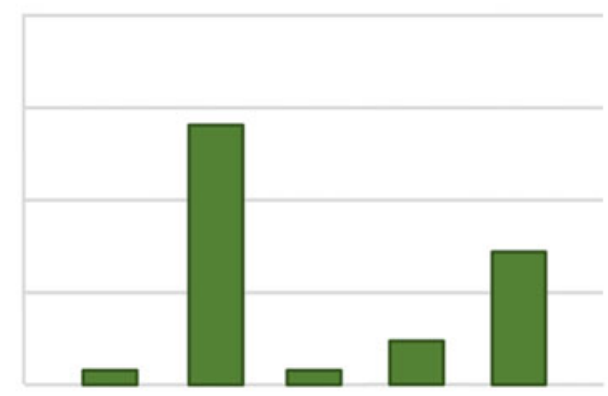

(f) KCA: peak season for wolf depredation

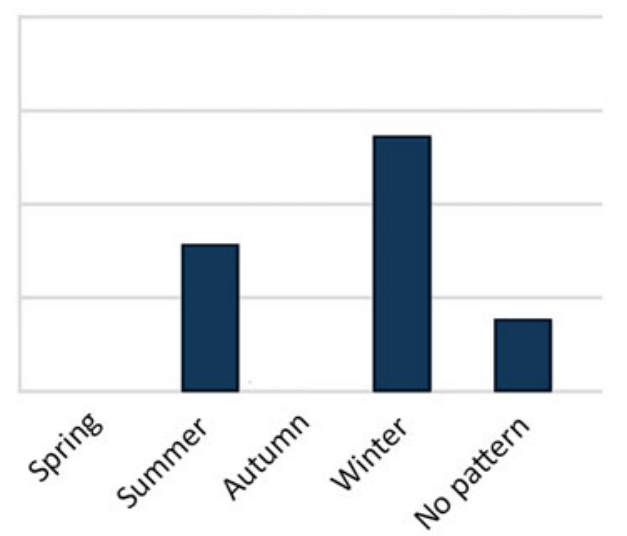

FIG. 3 The most problematic predator and the season with the most incidents of wolf depredation, as reported by local respondents during structured social surveys in Dolpa $(\mathrm{n}=27)$, Humla $(\mathrm{n}=32)$ and Kanchenjunga Conservation Area $(n=13)$, Nepal (Fig. 1). configuration (Wielgus \& Peebles, 2014; Chapron \& Treves, 2016; Treves et al., 2016).

To date, carnivore conservation in the Himalayas has focused on snow leopards, with insurance schemes and awareness programmes implemented locally (Mishra et al., 2003; Subba et al., 2017). In Kanchenjunga Conservation Area, where conservation programmes exist for the snow leopard and blue sheep, respondents expressed a positive attitude towards the snow leopard. These communities stated that they would support wolf conservation only if they received similar financial compensation for depredation by wolves. It is therefore crucial for wolf conservation to expand implementation of compensation to cover depredation by wolves, and the legal basis for this is already in place in Nepal's wildlife damage relief guidelines (GoN, 2015). We further recommend that governmental and non-governmental organizations working on carnivore conservation in the Himalayas of Nepal include all conflict-causing carnivores in their conservation programmes. This may involve facilitating self-financed depredation insurance schemes, protecting wild prey populations and managing livestock numbers, improving livestock protection, and increasing conservation awareness (Mishra, 1997). Payments to encourage coexistence can be a useful tool to increase local tolerance towards carnivores (Dickman et al., 2011). The implementation of conservation payments for species that are difficult to monitor and occur in remote areas (e.g. the snow leopard, Himalayan wolf and Eurasian lynx Lynx lynx in the Himalayas) can be tied to tangible performance criteria, such as maintaining the habitat and populations of 
wild prey species (e.g. blue sheep), with payments being contingent upon communities not killing any predators (Mishra et al., 2003; Nelson, 2009).

A first step towards the conservation of the Himalayan wolf in Nepal is to include it in existing conservation programmes, followed by expanding these across the entire region. These programmes can be informed by our insights into Himalayan wolf denning ecology, temporal-spatial wolf depredation patterns, and the associated perceptions of local communities.

\section{Acknowledgements}

We thank the Department of National Parks and Wildlife Conservation, Department of Forests, District Forest Office, Humla, Shey Phoksundo National Park, Dolpa and Kanchenjunga Conservation Areas for permits and support for this research. We thank all members of the field research teams, namely Pema Rikjin Lama, Tashi Namgyal Lama, Pemba Dorje Tamang, Kunjok Rangdol Tamang, Pasang Dorje Tamang, Tashi Dondup Lama, Bir Bahadur Sunar and Tshiring L. Lama, and the NGO Friends of Nature Nepal for its support. GW is supported by a Natural Motion Scholarship from the University of Oxford.

\section{Author contributions}

GW collected the field data, conducted the data analysis, conceived and designed the study, and drafted the article. NK participated in data collection and analysis, and in drafting the article. CSZ and DWM helped to conceive and design the study, and draft the article.

\section{References}

Aggarwal, R.K., Kivisild, T., Ramadevi, J. \& Singh, L. (2007) Mitochondrial DNA coding region sequences support the phylogenetic distinction of two Indian wolf species. Journal of Zoological Systematics and Evolutionary Research, 45, 163-172.

B A UER, K.M. (2004) High Frontiers: Dolpo and the Changing World of Himalayan Pastoralists. Columbia University Press, New York, USA.

Chapron, G. \& Treves, A. (2016) Blood does not buy goodwill: allowing culling increases poaching of a large carnivore. Proceedings of the Royal Society B, 283, http://dx.doi.org/10.1098/rspb.2015.2939.

Chetri, M., Jhala, Y.V., Jnawali, S.R., Subedi, N., Dhakal, M. \& Yumnam, B. (2016) Ancient Himalayan wolf (Canis lupus chanco) lineage in Upper Mustang of the Annapurna Conservation Area, Nepal. ZooKeys, 582, 143-156.

Dickman, A.J., Macdonald, E.A. \& Macdonald, D.W. (2011) A review of financial instruments to pay for predator conservation and encourage human-carnivore coexistence. Proceedings of the National Academy of Sciences of the United States of America, 108, 13937-13944.

Fox, J.L. \& Chundawat, R.S. (1995) Wolves in the Transhimalayan region of India: the continued survival of a low-density population. In Ecology and Conservation of Wolves in a Changing World (eds L.N. Carbyn, S.H. Fritts \& D.R. Seip), pp. 95-103. Canadian Circumpolar Institute, Edmonton, Canada.

Fuller, T.K. (1989) Population dynamics of wolves in north-central Minnesota. Wildlife Monographs, 105, 3-41.

GoN (Government of Nepal) (1973) National Parks and Wildlife Conservation Act. Kathmandu, Nepal.

GoN (Government of Nepal) (2015) Wildlife Damage Relief Guidelines 2012, First Amendment 2015. Ministry of Forests and Soil Conservation, Kathmandu, Nepal.

Jędrzejewski, W., Schmidt, K., Theuerkauf, J., Jędrzejewska, B., Selva, N., Zub, K. \& SZymura, L. (2002) Kill rates and predation by wolves on ungulate populations in Białowieża Primeval Forest (Poland). Ecology, 83, 1341-1356.

Jnawali, S.R., B aral, H.S., Lee, S., Acharya, K.P., Upadhyay, G.P., Pandey, M. et al. (compilers) (2011) The Status of Nepal's Mammals: The National Red List Series. Department of National Parks and Wildlife Conservation, Kathmandu, Nepal.

Mech, L.D. \& Boitani, L. (2003) Wolves: Behavior, Ecology, and Conservation. University of Chicago Press, Chicago, USA.

Miehe, G., Pendry, C. \& Chaudhary, R. (eds) (2016) Nepal: An Introduction to the Natural History, Ecology and Human Environment of the Himalayas. Royal Botanic Garden Edinburgh, Edinburgh, UK.

Mishra, C. (1997) Livestock depredation by large carnivores in the Indian trans-Himalaya: conflict perceptions and conservation prospects. Environmental Conservation, 24, 338-343.

Mishra, C., Allen, P., McCarthy, T., Madhusudan, M.D., Bayarjargal, A. \& Prins, H.H.T. (2003) The role of incentive programs in conserving the snow leopard. Conservation Biology, 17, 1512-1520.

Nelson, F. (2009) Developing payments for ecosystem services approaches to carnivore conservation. Human Dimensions of Wildlife, 14, 381-392.

Schaller, G.B. (1982) Stones of Silence: Journeys in the Himalaya. Bantam Books, New York, USA.

Sharma, D.K., Maldonado, J.E., Jhala, Y.V. \& Fleischer, R.C. (2004) Ancient wolf lineages in India. Proceedings of the Royal Society of London Series B: Biological Sciences, 271, S1-S4.

Sillero-Zubiri, C., Hoffmann, M. \& Macdonald, D. (2004) Canids: Foxes, Wolves, Jackals and Dogs. Status Survey and Conservation Action Plan. IUCN/SSC Canid Specialist Group, Gland, Switzerland, and Cambridge, UK.

Sub ва, S.A. (2012) Assessing the genetic status, distribution, prey selection and conservation issues of Himalayan wolf (Canis himalayensis) in Trans-Himalayan Dolpa, Nepal. MSc thesis. Lund University, Lund, Sweden.

Subba, S.A., Shrestha, A.K., Thapa, K., Malla, S., Thapa, G.J., Shrestha, S. et al. (2017) Distribution of grey wolves Canis lupus lupus in the Nepalese Himalaya: implications for conservation management. Oryx, 51, 403-406.

Trapp, J.R., Beier, P., Mack, C., Parsons, D.R. \& Paquet, P.C. (2008) Wolf, Canis lupus, den site selection in the Rocky Mountains. The Canadian Field-Naturalist, 122, 49-56.

Treves, A., Krofel, M. \& McManus, J. (2016) Predator control should not be a shot in the dark. Frontiers in Ecology and the Environment, 14, 380-388.

Tuyttens, F.A.M. \& Macdonald, D.W. (2000) Consequences of social perturbation for wildlife management and conservation. In Behaviour and Conservation (eds L.M. Gosling \& W.J. Sutherland), pp. 315-329. Cambridge University Press, Cambridge, UK.

Werhahn, G., Senn, H., Kaden, J., Joshi, J., Bhattarai, S., Kusi, N. et al. (2017) Phylogenetic evidence for the ancient Himalayan wolf: towards a clarification of its taxonomic status based on genetic sampling from western Nepal. Royal Society Open Science, 4, http://dx.doi.org/10.1098/rsos.170186. 
Wielgus, R.B. \& Peebles, K.A. (2014) Effects of wolf mortality on livestock depredations. PLOS ONE, 9(12), e113505.

\section{Biographical sketches}

Geraldine Werhahn is studying the phylogeny, ecology and conservation of wolves in the Himalayas and the Tibetan Plateau. N A RESH
KUSI is a wildlife researcher whose interests include predator-prey dynamics in the higher Himalayas, floral investigations, and exploration of the potential of wildlife tourism. CLAUDIO SILLERO-ZUBIRI is a conservation biologist working on carnivore conservation and human-wildlife conflict, and is the Chair of the IUCN SSC Canid Specialist Group. DAVID W. MACDOnAld has a background in behavioural ecology, especially of carnivores, and specializes in evidencebased solutions to conservation problems. 